\title{
LOWERING URIC ACID EFFICACY TEST OF THE COMBINED EXTRACT OF UNCARIA GAMBIR (HUNTER) ROXB. AND CAESALPINIA SAPPAN L. IN VIVO AND IN VITRO
}

\author{
SRI NINGSIH ${ }^{1 *}$, FAHRI FAHRUDIN ${ }^{2}$ \\ ${ }^{1}$ Center for Pharmaceutical and Medical Technology, Agency for the Assessment and Application of Technology (BPPT), Laptiab \\ Laboratory, 610-611 Building, Kawasan Puspiptek Serpong, Tangerang, Banten, Indonesia. ${ }^{2}$ Department of Biology, Faculty of Science and \\ Technology, Jakarta State Islamic University, Tangerang, Selatan, Banten, Indonesia. Email: sri.ningsih@bppt.go.id
}

Received: 19 March 2018, Revised and Accepted: 24 April 2018

ABSTRACT

Objective: Hyperuricemia (high uric acid levels) prevalence increased year by year. This study was aimed to elaborate the in vitro xanthine oxidase (XO) inhibitory activity and in vivo lowering hyperuricemic effect of Uncaria gambir (Hunter) Roxb) (gambir), Caesalpinia sappan L. (secang) and the combined extract of secang and gambir (formulae extract [FE]).

Methods: Gambir and secang extracts were prepared by maceration with ethanol and FE was the proportioned combination of these two extracts. XO inhibitory activity was determined by measuring the formation of uric acid in the xanthine/XO system in vitro using allopurinol as a positive control at $100 \mathrm{ug} / \mathrm{dL}$. Antioxidant activity was by 1,1-diphenyl-2-picrylhydrazyl radical reducing methods. The in vivo experiments were conducted in the oxonate-induced hyperuricemia rat model, in which FE was gavaged p.o. at the arrange dose of 75, 150, and 300 mg/kg bw for 2 weeks. Polyphenol content was measured using Folin-Ciocalteu reagent spectrophotometrically.

Results: The XO inhibitory activity of FE was $80 \%$ of allopurinol, while secang and gambir were $98 \%$ and $50 \%$, respectively. The strength was appropriate to the total polyphenol content, in which it decreased in the order of secang (99\%) > FE (86\%) > gambir (46\%). Furthermore, FE at all tested doses was able to decrease uric acid levels. FE also demonstrated antioxidant activity with a value of $74 \%$ relative to Vitamin $\mathrm{C}$ at 4 ug/mL.

Conclusion: These studies could be concluded that FE exhibited the ability to decrease uric acid level so that it was potential to be developed further as a uric acid-lowering agent.

Keywords: Gambir (Uncaria gambir (Hunter) Roxb), Secang (Caesalpinia sappan L.), Hyperuricemia, Xanthine oxidase, Blood lowering uric acid, 1,1-diphenyl-2-picrylhydrazyl radical, Polyphenol.

(c) 2018 The Authors. Published by Innovare Academic Sciences Pvt Ltd. This is an open access article under the CC BY license (http://creativecommons. org/licenses/by/4. 0/) DOI: http://dx.doi.org/10.22159/ajpcr.2018.v11i8.26020

\section{INTRODUCTION}

Hyperuricemia is a kind of disease that characterized by high blood uric acid. The prevalence increases year by year in the worldwide that influenced of modern lifestyle. The number of male sufferers is higher than that of women. In chronical condition, hyperuricemia can develop to be gout arthritis in which the saturated urate will deposit in the connective tissue and joint [1].

Uric acid is a metabolism product of xanthine oxidase (XO) enzyme from substrate xanthine. Blood monosodium urate monohydrate microcrystal can increase caused by high purine consumption, excessive uric acid production, and impaired uric acid excretion. Conventional hyperuricemia therapies were usually by managing diet and consuming the XO inhibiting drug such as allopurinol. However, the use of the chemical can rise side effects [1].

Chemical compounds contained in the plant will affect the pharmacological effects. Polyphenolic compounds, especially flavonoid, were claimed exhibiting antioxidant properties and demonstrating the XO inhibitory activity as well [2]. Indonesia is a country with mega diversities of medicinal plants. Thus, activities to find new natural compounds by utilizing biological resources are a strategic effort to find new drugs.

Gambir known as Uncaria gambir Hunter Roxb. belonging to Rubiaceae family is an Indonesian native plant. Previous studies had proven that gambir showed some pharmacological activity such as antibacterial, an inhibitor of alpha-glucosidase, anti-plaque on teeth, anti-inflammation, and antioxidant [3]. These activities were contributed by chemical compound contained on it, especially polyphenol compound flavonoids $(+)$ catechin that is about $40-80 \%$ of dry water extract weight [4].

Secang (Cesalpinia sappan L.) belonging to Fabaceae family is a common plant of oriental medicine that was claimed many beneficial functions such as food, medicine, dye industry, or as a protective plant. There were many pharmacological benefits such as antioxidant, anti-inflammatory, hepatoprotective, cytotoxic, and hypoglycemic activity. The antioxidative activity is the most widely studied and was attributed to the presence of phenolic compounds such as brazilin and flavonoids [5].

Traditionally, people prepared natural medicines with combining some herbs to obtain optimal therapy simultaneously. The advantage of combining natural product will be obtained, such as lowering effective dose rather than a single one and reducing side effect also. The aims of these studies were to investigate the uric acid lowering activity of the proportional combined extract of gambir and secang in vitro and in vivo. In vitro experiment was conducted on $\mathrm{XO}$ and xanthine system, and in vivo one was toward hyperuricemia rat model.

\section{MATERIALS AND METHODS}

Materials

Gambir fresh leaves (collected from Lima Puluhkota - West Sumatera Province) and Secang dry powder (obtained from Tawangmangu area) were determined before preparation for the experiment by Biology Research Center of Indonesian Institute of Sciences (LIPI). Chemicals 
used in this study were xanthin oxidase from bovine milk (Sigma, X4376-25UN, xanthine) (Sigma, X0626-10G), NaH2 PO4 (Merck), Na2 HPO4 (Merck), uric acid reagent kit (Diasys $($ ), EDTA (Merck), Follin-Ciocalteu (Sigma), Na2 CO3 (Merck), NaCl 0.9\% solution, bovine serum albumin (Sigma), DMSO (Merck), 1,1-diphenyl-2-picrylhydrazyl radical (DPPH) (Sigma), carboximethyl cellulose (CMC) (Pharmagrade), Ethanol (foodgrade).

\section{Sample preparation}

Dry powder gambir leaves were macerated with ethanol food grade at room temperature with agitation for 14-16 h. The filtrate was separated by filtering and dried under vacuum using vacuum rotavapour machine at the temperature of below $50^{\circ} \mathrm{C}$ until semisolid mass obtained. Dry powder secang wood was also extracted with the similar manner as above. FE was prepared by combining of those two semisolid extracts at the appropriated composition.

\section{XO inhibitory activity}

Sample solution was dissolved initially in DMSO (10 mg extract in 400 uL DMSO) and diluted using phosphate buffer pH 7.0 until $100 \mathrm{ppm}$ final concentration obtained. XO inhibitory activity was evaluated spectrophotometrically based on a previous paper with little modification [6]. Briefly, $100 \mathrm{uL}$ sample solution, $700 \mathrm{~mL}$ phosphate buffer $\mathrm{pH} 7.5$, and $160 \mathrm{uL}$ xanthine $150 \mathrm{uM}$, consecutively, were put and homogeneously mixed into a Quartz Cuvette. Then, was incubated at $37^{\circ} \mathrm{C}$ for $5 \mathrm{~min}$. The reaction was commenced by adding $40 \mathrm{uL}$ enzyme solution $(0.3 \mathrm{UI} / \mathrm{mL}$, the enzyme was dissolved in phosphate buffer $\mathrm{pH} 7.5$ ) and the absorbance was measured at the wavelength $290 \mathrm{~nm}$ using spectrophotometer UV-Vis at 1, 2, 3, and 4 min thereafter. Control enzyme and blank solutions were prepared by replacing the sample with phosphate buffer and enzyme solution with phosphate buffer, respectively. The slope was calculated from curve related between concentration and absorbance using Microsoft Excel program for windows. Each experiment was conducted in triplicate. Allopurinol at the same above concentration was used as a standard. Percentage of inhibition was calculated with this equation:

$$
\% \text { XO inhibition }=\frac{\text { Control slope-Sample slope }}{\text { Control slope }} \times 100
$$

\section{DPPH reducing activity}

Working solutions of samples were prepared by diluting stock solution until $4 \mathrm{ppm}$ final concentration using $\mathrm{MeOH}$. The stock solution was prepared by the same procedure as stated above. DPPH reducing activity was determined as a previous experiment [7]. The reaction was made by well mixing $3000 \mathrm{uL}$ sample solution and $150 \mathrm{uL}$ DPPH $0.004 \%$ (0.4 g in $100 \mathrm{ml} \mathrm{MeOH}$ ) solution and then incubating for $5 \mathrm{~min}$ in the dark condition at room temperature. The absorbance was measured every minute thereafter for 5 minutes using spectrophotometer UV-Vis at $517 \mathrm{~nm}$. The slope was determined by plotting the absorbance versus time using Microsoft Excel program for windows. A control solution was prepared by change sample solution with $\mathrm{MeOH}$. Blank solution was used $\mathrm{MeOH}$. Reaction was conducted in triplicate. Reducing activity was calculated with this equation:

$$
\% \text { Reducing activity }=\frac{\text { Controlslope-Sampleslope }}{\text { Controlslope }} \times 100
$$

\section{Total polyphenol determination}

Determination of total polyphenol was based on previous study spectrophotometrically with slightly modification [8]. Briefly, $10 \mathrm{mg}$ of each sample was added with 400 uL DMSO, sonicated until dissolved properly (stock solution). The stock solution was then diluted with aquadest into final concentration $10 \mathrm{ppm} .20 \mathrm{uL}$ sample solution, $1.580 \mathrm{uL}$ aquadest, and $100 \mathrm{uL}$ the Folin-Ciocalteu reagent were put into $2.0 \mathrm{~mL}$ disposable plastic microtube in order and mixed well in the dark. After $30 \mathrm{~s}$ to $8 \mathrm{~min}$ left, $300 \mathrm{uL} \mathrm{Na}_{2} \mathrm{SO}_{4} 20 \%$ was added to all tubes and shook to mix well for starting the reaction. The reaction was then incubated at $40^{\circ} \mathrm{C}$ for $30 \mathrm{~min}$ and read it absorbance at $765 \mathrm{~nm}$ using spectrophotometry UV-Vis. Blank solution was prepared by replacing the sample with aquadest. The experiment was carried out in triplicate. The standard was prepared by dissolving $20 \mathrm{mg}$ gallic acid with $400 \mathrm{uL}$ ethanol and added with aquadest to $5 \mathrm{ml}$ as a stock solution. Working solutions were prepared by diluting the stock solution with aquadest into a range of final concentration 1, 2, 3, 5, 8, and $10 \mathrm{ppm}$ and then treated in the same manner. The calibration curve was carried out by plotting each final concentration with its absorbance to obtain standard curve equation $(y=a x+b)$. The concentration of total polyphenol was calculated from the equation and reported as a percentage of gallic acid equivalent (GAE)/final concentration of the extract as the following equation:

\section{$\%$ Polyphenol $=\frac{\mathrm{GAE}(\mathrm{ppm})}{\text { Extract }(\mathrm{ppm})} \times$ Dilution factor $\times 100$}

\section{Blood uric acid lowering activity}

\section{Animals}

Animal used in this experiment was male, white rats strain Sprague Dawley rats (2-2.5 months), 110-150 g body weight, purchased from BPOM (Indonesian FDA). The experiment was approved by the Ethics Committee of Medicinal Faculty of Indonesian University (No. 123 H2.F1/ETIK/2014). Rats housed in polycarbonate cages, 4-5 rats each cage, with bedding of husk were given food and water ad libitum. The environmental condition was maintained at the temperature of $21 \pm 2^{\circ} \mathrm{C}$ and the humidity of $30-70 \%$ under 12 dark/ light cycles. Before being used, rats were acclimatized to laboratory condition for 7 days before initiation of dosing.

\section{Animal treatment}

Serum uric acid lowering activity was determined based on a previous study $[9,10]$ with modification. Briefly, animals were grouped randomly into 6 groups 5 rats each group. Groups 1,2, and 3 were treated with $\mathrm{FE}$ at the dose of 75, 150, and $300 \mathrm{mg} / \mathrm{kg}$ bw p.o. daily, respectively, for 4 consecutive weeks. Group 4 was as positive control given allopurinol at the dose of $13.5 \mathrm{mg} / \mathrm{kg}$ bw p.o. FE and allopurinol were suspended in CMC $0.5 \%$ solution, respectively, before be given into rats with administration volume $1 \mathrm{~mL} / 100 \mathrm{~g}$ bw Group 5 was as a model group treated (negative group) with CMC $0.5 \%$ p.o. Group 6 was as normal group administrated carrier CMC $0.5 \%$ solution p.o. All animals, except the normal group given CMC $0.5 \%$ i.p., were induced with single dose of potassium oxonic suspension at the dose of $250 \mathrm{mg} / \mathrm{kg}$ bw i.p. $1 \mathrm{~h}$ after the past 2 weeks FE or allopurinol treatment. The 14-16 h blood fasting was collected from sinus orbital $2 \mathrm{~h}$ after potassium oxonic induction in plastic disposable with EDTA, and then plasma was separated using centrifugation at $10,000 \mathrm{rpm}$, temperature of $40 \mathrm{C}$ for 10 min. Plasma uric acid was determined using uric acid diagnostic kit Diasys ${ }^{\circledR}$ using spectrophotometer UV-Vis.

\section{Data analysis}

Data were presented as a means \pm standard error of mean and analyzed statistically by an ANOVA method for parametric data or Kruskall-Wallis method for nonparametric data and then followed by LSD or Mann-Whitney method, respectively, for determining the differences between groups. Statistic evaluation was conducted using SPPS 11 program with significance value $\mathrm{p}=0.05$.

\section{RESULTS AND DISCUSSION}

The efforts of finding new products with pharmacological properties from plant sources increased significantly in accordance with the trend back to nature. Natural agents proved demonstrating some benefits as curing, prevention, and management of diseases. Secang and gambir are well-known medicinal plants and proved to have pharmacological activity. The proportioned combination of secang and gambir semisolid extracts evaluated in this study showed the effect of lowering uric acid production and reducing DPPH radical. 
The decreasing activities of uric acid production were evaluated on xanthine/XO system in vitro and hyperuricemia rat model in vivo.

The results of XO inhibitory measurement of all samples were depicted at Fig. 1. The inhibitory activity was sated as percent relative to the positive control allopurinol.

It was shown that all tested samples (gambir, secang, and FE) demonstrated XO inhibitory activity. The power of secang extract was higher than gambir extract ( $98 \%$ vs. $50 \%$ ), and the activity of FE was among them (80\%). The strength of inhibition was in the following order secang $>\mathrm{FE}>$ gambir. The combination between secang and gambir extract (FE) exhibited non-synergistic XO inhibitory effect in vitro. This reduction activity of $\mathrm{FE}$ might be due to a negative interaction between compounds in the FE, but it needed to be elaborated further. Individual herbal extracts consisted of a complex mixture of bioactive compounds, concomitant agents, and other minor substances among which interactions can occur leading to synergistic or non-synergistic effects.

The in vitro studies of the pharmacological effect of the proportioned combination of the natural product had been elaborated previously [11,12]. The combination of Sonchus arvensis and Anredera cordifolia extract at 1:1 portion exhibited lower inhibition than of single extract [12]. The 1:1 ratio of peppermint and sage extract significantly inhibited SW-480 colon cancer cell growth higher than the 1:1 ratio of rosemary and sage extract, although peppermint extracts showed lower inhibition than rosemary extracts [13]. It was demonstrated that to obtain the optimal synergism effect, it was needed to combine the proper ratio and kind of extracts.

Secang inhibitory XO activities had been elaborated by the previous researcher. Methanolic extract of secang was able to suppress $50 \%$ XO activity at the concentration of $14.2 \mathrm{ug} / \mathrm{mL}\left(\mathrm{IC}_{50}\right)$ (5 nguyen). Neosappanone, the compound isolated from secang, showed a dosedependent inhibitory activity with $\mathrm{IC}_{50}$ of $29.7 \mu \mathrm{M}$. However, the activity was 10 -fold less potent than the positive control allopurinol $(2.6 \mu \mathrm{M})[14]$.

Analysis of the polyphenol content of each tested sample demonstrated the same order with the activity of XO inhibitory. The polyphenol content was in the order followed secang $>$ FE $>$ gambir (Fig. 2).

It exhibited that polyphenolic compound contributed to XO inhibitory activity. The previous study reported that polyphenolic flavonoid compounds could inhibit XO activity. To obtain a high XO inhibition, there are some main roles of SAR (structure-activity relationships) condition as follows (i) planar shape (i.e. no-sp ${ }^{3}$ carbons are present; flavones are far more active than flavanones), (ii) $\mathrm{OH}$-groups at $\mathrm{C}-5$ and C-7 are important for strong activity, and (iii) double bond between C2 and C3. Flavonols, isoflavones, and anthocyanidins are less active than flavones [15]. The substitution hydroxyl group at position C3 and C7 with glucose or methyl moiety could decrease the activity caused by hindering the interaction between enzyme and compound $[16,17]$. Flavone group was the highest XO inhibitory activity. Polyphenol compounds, including flavonoid, delivered some biological, and pharmacological activities such as antioxidative, antibacterial, antiviral, and antimutagenic effects. Many of them also provided inhibition toward several enzymes such as $\mathrm{XO}$, cyclooxygenase, lipoxygenase, and phosphoinositide 3-kinase [18]. Owen and Tim (1999) [19] reported that there were three types of relationships between the polyphenols level and pharmacological activity, namely (i) polyphenolic compound content high and enzyme inhibition high, (ii) polyphenolic compound content high and enzyme inhibition low, and (iii) polyphenolic compound content low and enzyme inhibition high. The previous experiment had been proven the XO inhibitory activity some kind of gambir extracts in vitro [4].

The antioxidant activity of each sample was measured with the DPPH reducing method. DPPH is a stable radical compound in which it had been used widely in the evaluation antioxidant activity of

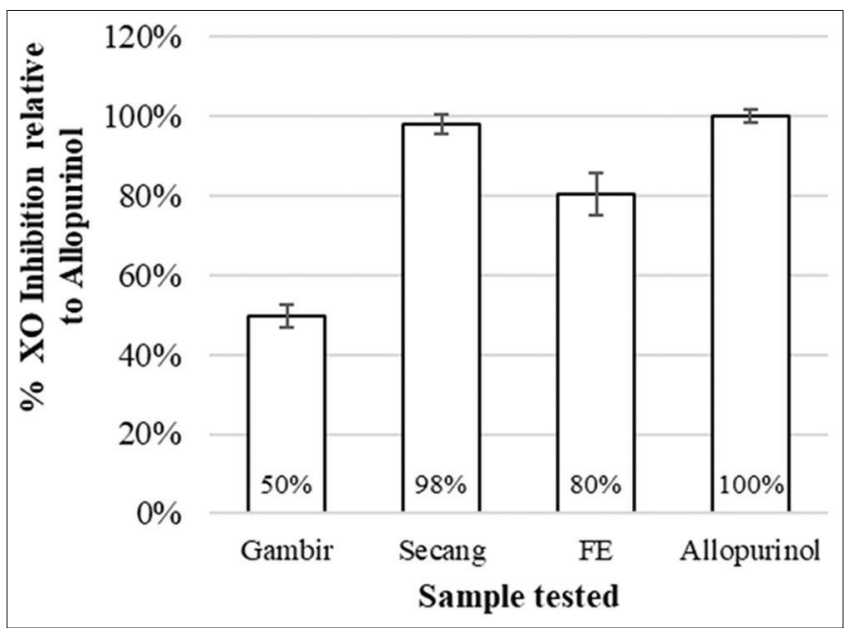

Fig. 1: The activity of xanthine oxidase inhibition of each sample tested. Values were an average of three measurements and conducted at the final concentration $100 \mathrm{ppm}$. Allopurinol was as a positive control. Value $=[($ Control slope-Sample slope $) /$ Control slope] $\times 100 \%$

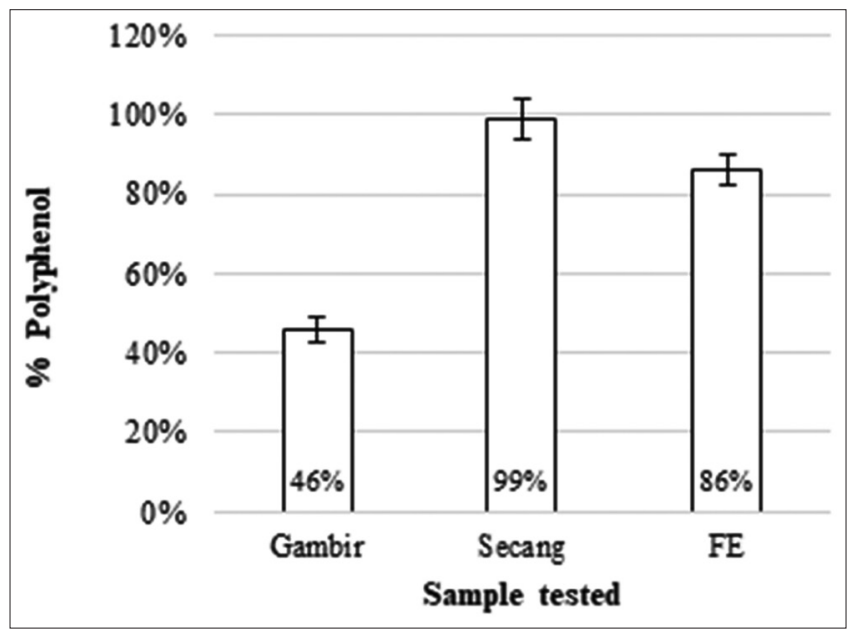

Fig. 2: Polyphenol content of each sample tested. Polyphenol content was determined using Folin-Ciocalteu reagent spectrophotometrically. Values were an average of three measurements from triplicate. \% polyphenol=[GAE (ppm)/ Extract (ppm)] $\times$ dilution factor $\times 100 \%$

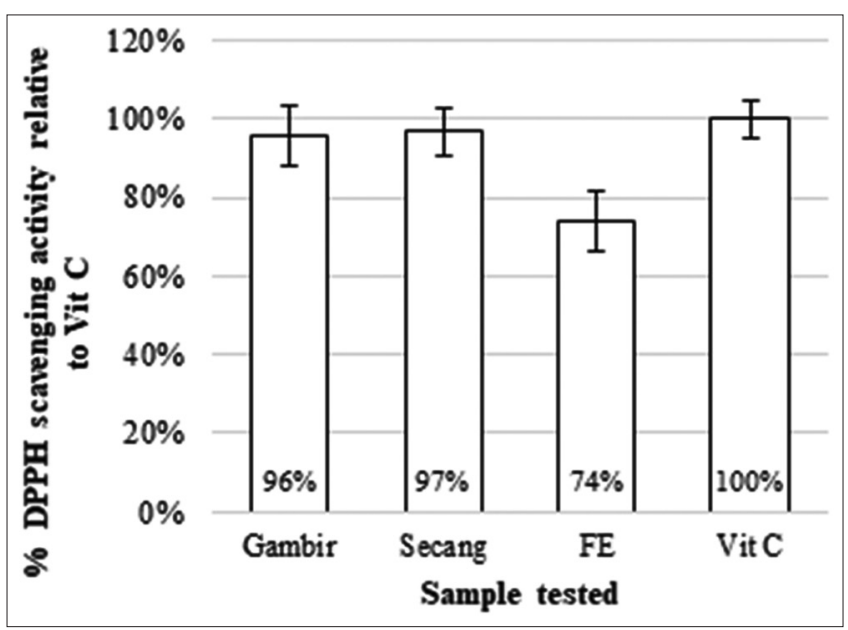

Fig. 3: 1,1-diphenyl-2-picrylhydrazyl radical reducing the activity of the sample tested relative to the positive control 


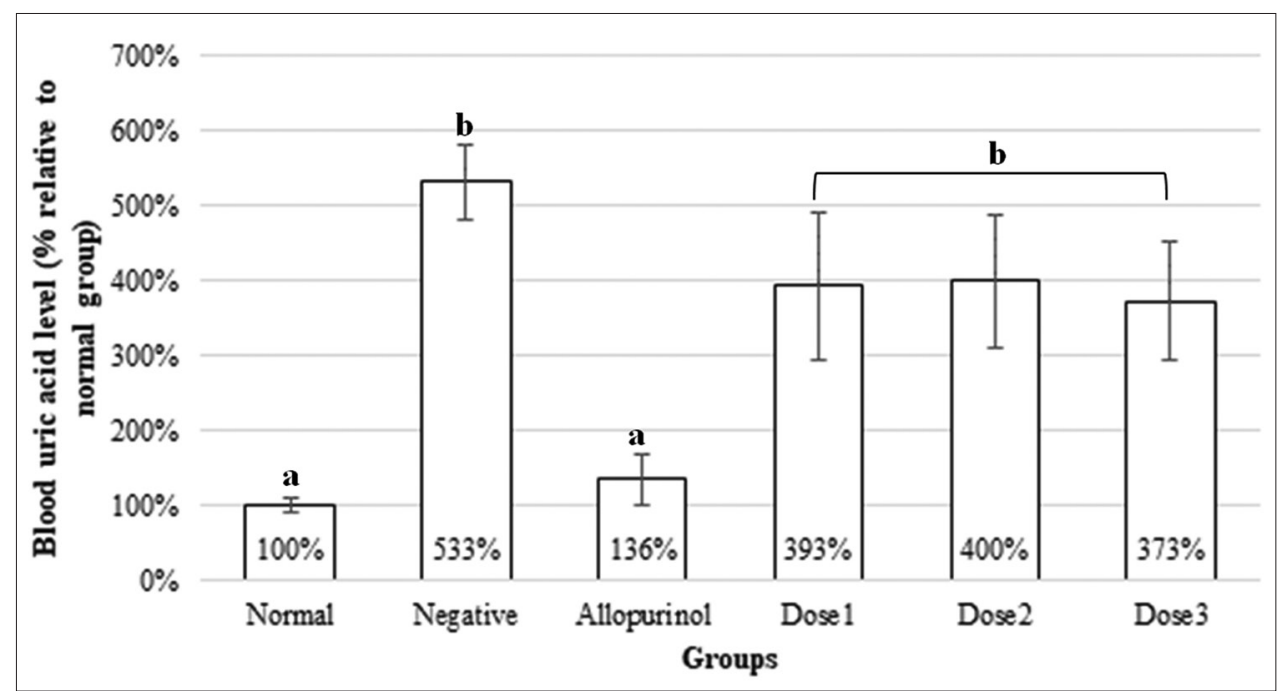

Fig. 4: Uric acid level relative to negative control. Values were an average of percent lowering uric acid compared to negative group measured at 2 weeks after treatment. Value $=$ (uric acid level of treatment group/uric acid level of negative group) $\times 100 \%$. Values of each group were analyzed statistically compared to the normal group, and the different alphabet was mean different statistically ( $<<0.05$ ). $\mathrm{N}=5$ rats each group

compound both synthetic and natural products. In this mechanism, the antioxidant compound will donate hydrogen to DPPH produced stable, non-radical DPPH-H. This reaction will change the color from purple to pink [20]. The result was presented as percent compared to the positive control Vitamin C (Fig. 3). The antioxidant activity evaluation showed that both gambir and secang extract demonstrated the same level, namely $96 \%$ and $97 \%$, respectively, while that of FE was $74 \%$.

The previous study stated that there was a correlation between polyphenol content and antioxidant activity $[3,21]$. The results of DPPH reducing the activity of secang and gambir extract were in accordance with previous studies $[3,22]$. Both gum and leaf extracts of gambir demonstrated and lipid peroxidation inhibition on rat liver homogenate in vitro [3]. Both ethanolic and water extracts of secang possessed significant free radical scavenging and reducing power [22]. These studies showed that DPPH reducing the activity of each extract was not always in line with the total polyphenol content (Fig. 2). $\mathrm{DPPH}$ reducing power was in the following order, secang $>$ gambir $>\mathrm{FE}$ and the polyphenol content was secang $>\mathrm{FE}>$ gambir. The gambir polyphenolic compound was lower than the FE, but the DPPH reducing the activity of gambir was higher than FE. The result indicated that there was no linear relationship between antioxidant activity and total polyphenol content. It was likely that DPPH activity was contributed by other compounds in the extract rather than polyphenolic compounds only. The other possibility was due to FE comprising of both extract, gambir, and secang so that the content of the single extract in the FE was lesser than each extract. It caused the hydrogen donation mechanism was less strong than being performed by single extract at the same concentration. FE probably had other antioxidant mechanisms such as free radical inhibitors and free electron donation, but these mechanisms were needed to be explored. Evaluation antioxidant activity was important in the efforts to find a new agent for treating hyperuricemia. It was due that the side product of purine metabolism is radical compounds caused by cell damage $[2,6]$

Fig. 4 depicted blood uric acid levels after FE treatment for 2 weeks relative to normal. Induction of potassium oxonate can increase blood uric acid up to 5-fold, and then FE administration at all of the doses p.o. could decrease uric acid level, but it was still higher than normal group level. Statistically, the uric acid level of the treatment groups was significantly different compared to normal $(\mathrm{p}<0.05)$. In addition, when compared to positive control allopurinol, the uric acid levels of the three
FE groups were still higher also. Statistically, they were significantly different compared to allopurinol $(\mathrm{p}<0.05)$. This means that the ability of FE in all three doses in lowering blood uric acid levels was still below than allopurinol.

From these studies demonstrated that the efficacy results of in vitro and in vivo evaluation were different. In vitro assay (Fig. 1), it was shown that the FE was able to inhibit XO activity of $80 \%$ compared to positive control allopurinol. This result was in accordance with a previous study [4]. However, in vivo evaluation (Fig. 4), it was displayed that blood uric acid lowering activity of $\mathrm{FE}$ was slightly less active than allopurinol. The serum uric acid of FE was not different to negative group ( $p>0.05)$. It is likely that blood uric acid mechanism in vivo was more complex than inhibiting XO in vitro. Moreover, it was needed further study to establish the right combination ratio, dose of administration and mechanism in lowering blood uric acid.

The blood uric acid level depends on three conditions, namely the consumption of high purine food, metabolism to produce uric acid, and uric acid excretion. Hyperuricemia is due to especially from increasing $\mathrm{XO}$ activity cause high uric acid level and decreasing excretion process, or both them [1]. As indicated above that FE was able to suppress the XO power in vitro; however, the ability to decrease blood uric acid in the animal model was not significant enough. It is likely that the excreting uric acid activity of FE was slightly weak. Thus, further elaboration of the decreasing uric acid mechanism of FE was required.

\section{CONCLUSIONS}

These studies could be concluded that FE inhibited XO activity in vitro and decreased blood uric acid in hyperuricemia potassium oxonate-induced rat in vivo. Pharmacological activities were likely contributed by polyphenol content. FE had potential to be developed as lowering uric acid substance.

\section{ACKNOWLEDGMENT}

The authors would like to thank deeply toward The Ministry of Research, Technology and Higher Education, Republic of Indonesia with Insentif Sinas Ristek 2015 Program for providing this research funding.

\section{AUTHOR'S CONTRIBUTION}

Sri Ningsih has provided the design, intellectual content, innovation and protocol for conducting the experiment, analysis of obtaining data, 
and preparing the manuscript along with mentorship. Fahri Fahrudin, has majority performed the experiment in the laboratory.

\section{CONFLICTS OF INTEREST}

The authors declare that there are no conflicts of interest regarding the publication of this article.

\section{REFERENCES}

1. Ling X, Bochu W. A review of phytotherapy of gout: Perspective of new pharmacological treatments. Pharmazie 2014;69:243-56.

2. Spanou C, Veskoukis AS, Kerasioti T, Kontou M, Angelis A, Aligiannis $\mathrm{N}$, et al. Flavonoid glycosides isolated from unique legume plant extracts as novel inhibitors of xanthine oxidase. PLoS One 2012; 7:e32214.

3. Ningsih S, Fachrudin F, Rismana E, Purwaningsih EH, Sumaryono S, Jusman SW. Evaluation of antilipid peroxidation activity of gambir extract on liver homogenat in vitro. Int J PharmTech Res 2014;6:982-9.

4. Rismana E, Ningsih S, Fachrudin F. In vitro study of xanthine oxidase inhibitory of gambir (Uncaria gambir) hunter roxb extracts. Pharmacogn J 2017;9:862-5.

5. Nguyen MT, Awale S, Tezuka Y, Tran QL, Kadota S. Neosappanone A, a xanthine oxidase (XO) inhibitory dimeric methanodibenzoxocinone with a new carbon skeleton from Caesalpinia sappan. Tetrahedron Lett 2004;45:8519-22.

6. Dew TP, Day AJ, Morgan MR. Xanthine oxidase activity in vitro: Effects of food extracts and components. J Agric Food Chem 2005;53:651015.

7. Pour BM, Jothy SL, Latha LY, Chen Y, Sasidharan S. Antioxidant activity of methanol extracts of different parts of Lantana camara. Asian Pac J Trop Biomed 2012;2:960-5.

8. Waterhouse A. Folin-Ciocalteau Micro Method for Total Phenol in Wine. Waterhouse Lab., University of California. Accessed from: http://www.waterhouse.ucdavis.edu/faqs/davis-info. [Last accessed on 2013 Oct 17].

9. Haidari F, Rashidi MR, Keshavarz SA, Mahboob SA, Eshraghian MR, Shahi MM, et al. Effects of onion on serum uric acid levels and hepatic xanthine dehydrogenase/xanthine oxidase activities in hyperuricemic rats. Pak J Biol Sci 2008;11:1779-84.

10. Boussoualim N, Baghiani A, Krache I, Trabsa H, Kenouf S, Arrar L. Inhibitory effects of Anchusa azurea extracts on xanthine oxidase activity and its hypouricemic effects on mice. Int J Pharm Pharm Sci 2015;7:195-9.
11. Widyarini KD, Sukandar EY, Fidrianny I. Xanthine oxidase inhibitory and antihyperuricemic activities of Anredera cordifolia (ten) steenis, Sonchus arvensis 1 , and its combination. Int $\mathrm{J}$ Pharm Pharm Sci 2015;7:86-90.

12. Zhou X, Seto SW, Chang D, Kiat H, Razmovski-Naumovski V, Chan K, et al. Synergistic effects of Chinese herbal medicine: A Comprehensive review of methodology and current research. Front Pharmacol 2016;7:201

13. Yi W, Wetzstein HY. Anti-tumorigenic activity of five culinary and medicinal herbs grown under greenhouse conditions and their combination effects. J Sci Food Agric 2011;91:1849-54

14. Zanin JLB, Carvalho BA, Martineli PS, Santos MH, Lago JH, Sartorelli P, et al. The genus Caesalpinia L. (Caesalpiniaceae): Phytochemical and pharmacological characteristics: Review. Molecules 2012;17:7887 902.

15. Hunyadi A, Martins A, Danko B, Chuang D, Trouillas P, Chang FR, et al. Discovery of the first non-planar flavonoid that can strongly inhibit xanthine oxidase: Protoapigenone 10-O-propargyl ether. Tetrahedron Lett 2013;54:6529-32.

16. Cos P, Ying L, Calomme M, Hu JP, Cimanga K, Poel BV, et al. Structureactivity relationship and classification of flavonoids as inhibitors of xanthine oxidase and superoxide scavengers. J Nat Prod 1998;61:71-6.

17. Wong YP, Ching R, Chuah SP, Koh RY, Ling AP. Antioxidant and Xanthine Oxidase Inhibitory Activities of Swietenia macrophylla and Punica granatum. International Conference on Biological, Environment and Food Engineering (BEFE-2014), Bali (Indonesia). 2014. p. 4-5.

18. Lin CM, Chen CS, Chen CT, Lin JK, Liang YC. Molecular modeling of flavonoids that inhibits xanthine oxidase. Biochem Biophys Res Comm 2002;294:167-72.

19. Owen PL, John T. Xanthine oxidase inhibitory activity of northeastern North American plant remedies used for gout. J Ethnopharmacol 1999;64:149-60.

20. Sahgal G, Ramanathan S, Sasidharan S, Mordi MN, Ismail S, Mansor SM. In vitro antioxidant and xanthine oxidase inhibitory activities of Methanolic Swietenia mahagoni seed extracts. Molecules 2009; 14:4476-85.

21. Bandara CJ, Karunaratne DN, Wickramasinghe A, Wijesundara DS, Bandara BM, Karunaratne V. Total polyphenol content and antioxidant and cytotoxic activities of the Sri Lankan endemic plant genus Schumacheria. Int J Pharm Pharm Sci 2015;7:465-7.

22. Kadchumsang S, Sirisa-Ard P, Sookkhee S, Chansakaow S. Antibacterial and antioxidant activities of lanna medicinal plants used in Mahoog formula. Int J Pharm Pharm Sci 2015;7:366-70. 